\title{
The mediating role of psychological capital on the association between workplace violence and professional identity among Chinese doctors: a cross-sectional study
}

This article was published in the following Dove Press journal:

Psychology Research and Behavior Management

\section{Tian Qiu \\ Chunli Liu \\ Hao Huang \\ Shihan Yang \\ Zhihui Gu \\ Fangqiong Tian \\ Hui Wu}

Department of Social Medicine, School of Public Health, China Medical University, Shenyang, Liaoning Province, People's Republic of China
Correspondence: Hui Wu

Department of Social Medicine, School of Public Health, China Medical University,

No. 77 Puhe Road, Shenyang North New Area, Shenyang II0I22, People's Republic of China

Tel +861 8900910568

Email hwu@cmu.edu.cn
Background: Workplace violence (WPV) and psychological capital (PsyCap) are linked to professional identity, however, little research has examined how WPV is associated with professional identity via PsyCap. This study is aimed to examine the association between WPV and professional identity, and to further explore whether PsyCap can serve as a mediator between WPV and professional identity among Chinese doctors.

Materials and methods: A cross-sectional study was conducted from November to December in Liaoning Province in China, in 2017. The study used a questionnaire consisting of Workplace Violence Scale (WVS), Occupational Identity Scale (OIS), Psychological Capital Questionnaire (PCQ), as well as questions about demographic characteristics. Out of 1200 doctors, 995 (effective response rate of 82.92\%) completed the questionnaire survey and became our final subjects. Hierarchical multiple regression and the asymptotic and resampling strategies were conducted to explore the mediating role of PsyCap in the relationship between WPV and professional identity.

Results: After adjusting for demographic characteristics, WPV was negatively associated with professional identity $(\beta=-0.37 ; P<0.01)$. Mediation analysis indicated that PsyCap was a mediator in the relationship between WPV and professional identity. Two dimensions of PsyCap: self-efficacy $(\mathrm{a} * \mathrm{~b}=-0.04$, BCa 95\% CI: $(-0.08,-0.01)$; $P<0.01)$ and hope $\left(\mathrm{a}^{*} \mathrm{~b}=-0.04, \mathrm{BCa} 95 \% \mathrm{CI}:(-0.08,-0.01) ; P<0.01\right)$ also did exhibit mediating effects in the relationship between WPV and professional identity. The proportion of self-efficacy, hope and PsyCap mediation was $10.73 \%, 10.77 \%, 36.22 \%$ for professional identity respectively.

Conclusion: These results provided evidence that PsyCap could mediate the association between WPV and professional identity. To increase the level of professional identity, positive interventions targeting PsyCap should be taken, with a focus on self-efficacy and hope.

Keywords: professional identity, workplace violence, psychological capital, Chinese doctors

\section{Introduction}

Professional identity in medicine is a representation of self, achieved in stages over time during which the characteristics, values, and norms of the medical profession are internalized. It results in an individual thinking, acting, and feeling like a physician. ${ }^{1}$ According to previous studies, the level of professional identity 
among doctors was relatively low compared with nurses. ${ }^{2-4}$ Low level of professional identity could undermine doctors' work performance and increase burnout and turnover intention. ${ }^{5}$ Eventually, low level of professional identity would negatively affect doctors' psychological health and the quality of medical service. According to a survey related to malignant injury medical event in $2012,78.6 \%$ of doctors were doubtful about their choices at the first time, some of them wouldn't allow their children to be engaged in clinical work. ${ }^{6}$ High level of professional identity could implicitly help doctors to motivate patients' treatment and ultimately make patients' well-being better. ${ }^{7}$ Therefore, exploring how to improve doctors' professional identity is crucial to improve Chinese doctors' psychological health, and more importantly, to increase the quality of health care services.

Previous studies found that the level of professional identity is affected by many factors, including: working environment, personality, positive interpersonal experiences, etc. ${ }^{8,9}$ Noticeably, workplace violence (WPV) is becoming increasingly prevalent, and makes medical practice a risk job in China. ${ }^{13}$ WPV was defined as incidents where staff were abused, threatened or assaulted in circumstances related to their work, including commuting from work, involving explicit or implicit challenges to safety, well-being or health. ${ }^{14}$ WPV consists of two parts: physical and psychological violence. Physical violence refers to the intentional usage of physical force, including beating and hitting. While psychological violence is the behavior such as verbal abuses or sexual harassment. ${ }^{15}$ Previous surveys showed that almost $80-95 \%$ doctors were susceptible to WPV. ${ }^{10-12}$ WPV in hospitals can leads to serious consequences, such as frequent absenteeism, reduced work efficiency, increased occupational strain and turnover. ${ }^{12}$ In addition, it could affect the quality of health services via negatively influencing confidence of medical staff. ${ }^{16}$ As a result, reducing the occurrence of WPV is important for doctors' professional outcomes. ${ }^{17}$ Besides, WPV was significantly negatively correlated with general self-efficacy, which is one of PsyCap's dimensions. ${ }^{18}$ Although WPV was found to be negatively related to professional identity in other groups before, ${ }^{19}$ the association between WPV and professional identity among Chinese doctors is not clear.

With an increasing recognition of the value of positive organizational behavior, organizations sought to facilitate employees' physical and mental health by strengthening the psychological resources of doctors. ${ }^{20}$ Psychological capital (PsyCap) is a vital concept drawn from positive organizational behavior and has been reported as a positive resource for combating doctors' stress and turnover. ${ }^{21}$ There are four core components in PsyCap, including self-efficacy, optimism, resilience, and hope. ${ }^{22,23}$ Recent researches suggested that PsyCap were related to WPV as well as professional identity. For example, a study found that increased PsyCap was negatively related to WPV. ${ }^{17}$ WPV was negatively correlated with general self-efficacy, which is one of the related dimensions of PsyCap. ${ }^{18}$ Besides, general self-efficacy can modify effects of WPV on health care workers' stress and job satisfaction among Chinese doctors. ${ }^{18}$ Another study suggested that PsyCap was positively correlated with professional identity. ${ }^{22}$ Additionally, a previous research suggested that PsyCap played a mediator in the relationship between work-family conflict and burnout among Chinese doctors. ${ }^{23}$ However, to our knowledge, PsyCap as a mediator in the relationship between WPV and professional identity has not been absolutely confirmed yet, especially among Chinese doctors. Based on the above studies about the PsyCap and the related variables, we have hypothesized whether the association between WPV and professional identity among Chinese doctors is mediated by PsyCap.

The aim of the present study is firstly to explore the relationship between WPV and professional identity among Chinese doctors. Secondly, we will examine the mediating role of PsyCap in the relationship between WPV and professional identity. Finally, we want to propose intervention strategies to prevent doctors from WPV and to improve doctors' professional identity.

\section{Materials and methods}

\section{Ethics statement}

The study protocol was in accordance with the ethical standards and was approved by the Ethics Committee of China Medical University. Written informed consent was obtained from each participant. Information collected from all participants was kept confidential and anonymous.

\section{Study design and sample}

A cross-sectional study was conducted in Dalian city, Liaoning province of China from November to December in 2017; Based on the geographic division, Dalian city consists of five geographic regions (eastern, western, central, southern, and northern). One large hospital (>500 beds) was randomly selected in each district. A total of five hospitals were selected eventually. 
Then we randomly selected medical staffs. 1200 doctors were selected to do the questionnaires, in which 240 were selected in each hospital. Complete responses were obtained from 995 participants, yielding an effective response rate of $82.92 \%$.

\section{Demographic characteristics}

Age, gender, educational situation, marital status was obtained in this study. "Age" was categorized as " $\leq 30$ ", "31-39" and " $\geq 40$ ". "Gender" was categorized as "Male" and "Female", "Educational situation" was categorized as "Undergraduate or lower" and "Master or higher". "Marital status" was categorized as "single/divorced/separated/ widow" and "marriage/cohabitation".

\section{Measurement of professional identity}

Professional identity was measured with the Occupational Identity Scale (OIS), developed by Tyler and McCallum. ${ }^{24}$ The Chinese version of the OIS was translated by Cai (2003), ${ }^{25}$ which was based on the OIS (Tyler \& McCallum, 1998). The scale consists of 10 items (eg, "My present job makes me feel very proud"). All the items were scored from 1 (absolutely inconsistent) to 5 (absolutely consistent). The answers were then summed up to create a total score from 10 to 50, with higher scores indicating higher levels of professional identity. The Chinese version of the OIS has been used widely in Chinese population and demonstrated satisfactory reliability. ${ }^{25}$ In the present survey, the Cronbach's $\alpha$ for the total scale was 0.95 . The confirmatory factor analysis confirmed that the OIS had satisfactory validity (Root-Mean-Square Error of Approximation (RMSEA) $=0.07$, Comparative Fit Index $(\mathrm{CFI})=0.98$, Goodness-of-Fit Index $(\mathrm{GFI})=0.96$, Adjusted Goodness-of-Fit Index (AGFI) $=0.93$, Tucker-Lewis Index (TLI) $=0.97$, and Normal Fit Index $(\mathrm{NFI})=0.97)$.

\section{Measurement of WPV}

WPV was measured with the Workplace Violence Scale (WVS), developed by Schat. ${ }^{26}$ Combined with Chinese conditions and the original scoring methods, the Chinese version of WVS was developed by Wang Peixi. ${ }^{27,28}$ The scale consists of 5 items. (eg, "The frequency of suffering from physical assaulting"). All the items were scored from 0 (never experienced) to 3 (4 times or above). The score of the WVS was created by adding the scores for each item, ranging from 0 to 15 , with higher scores indicating a higher frequency of experiencing WPV. The Chinese version of the WVS has been widely used in Chinese studies with a satisfying reliability. ${ }^{26,27,29}$ In this study, the Cronbach's $\alpha$ for the WVS was 0.88 . The confirmatory factor analysis confirmed that the WVS had satisfactory validity (RMSEA $=0.01$, CFI $=1.00$, GFI $=1.00$, AGFI $=0.99$, $\mathrm{TLI}=1.00$, and NFI $=1.00$ ).

\section{Measurement of PsyCap}

PsyCap was measured with the Psychological Capital Questionnaire (PCQ), which was developed by Luthans et al. $^{30}$ The PCQ consists of 24 items and four dimensions: self-efficacy (6 items), hope (6 items), resilience (6 items) and optimism ( 6 items). All the items were scored on a Likert scale from 1 (strongly disagree) to 6 (strongly agree). In this study, we summed up the 24 questions and got an average score as an indicator for total PsyCap. Higher values indicated higher level of PsyCap and the four components. The Chinese version of the PCQ has been widely used in Chinese studies and the reliability is satisfying. ${ }^{31-33}$ Cronbach's $\alpha$ coefficient of self-efficacy, hope, resilience and optimism subscales and the total scale were 0.95 , $0.94,0.93,0.93$ and 0.98 , respectively. The confirmatory factor analysis confirmed that the PCQ had satisfactory validity $($ RMSEA $=0.06$, CFI $=0.98$, GFI $=0.94$, AGFI $=0.90$, TLI $=0.96$, and NFI $=0.97$ ).

\section{Statistical analyses}

The demographic variables were described with mean, standard deviation (SD), number (n) and percentage (\%) as appropriate. Differences in continuous variables were examined by independent-sample $t$-test or one-way ANOVA. Pearson's correlation analysis was used appropriately to examine correlations among WPV, PsyCap and its components and professional identity. In this study, demographic variables (age, gender, marital status and educational situation), professional identity, workplace violence, psychological capital and its dimensions were considered into multicollinearity testing. VIF (Variance Inflation Factor) values $<10$, which indicated that multicollinearity was not an issue in the estimate. Hierarchical multiple regression was performed to examine the mediating role of PsyCap on the associations of WPV with professional identity. In block 1 of the analysis, all demographic variables (age, gender, educational situation and marital status) were added as controlling variables; in block 2, WPV was added as an independent variable. In block 3, two models were 
conducted, respectively. In block 3' s model 1 , four components of PsyCap were added as mediators. In block 3' s model 2, PsyCap was added as a mediator. If the c' path coefficient in Block 2 was smaller than that of the $\mathrm{c}$ path coefficient in Block 1, or c' is statistically insignificant, it was speculated that the mediation may exist. The variables in the models were centralized before regression analysis.

We used the asymptotic and resampling strategies developed by Preacher and Hayes ${ }^{34}$ to examine Psycap as a potential mediator on the association between WPV and professional identity. WPV was modeled as independent variable, with professional identity as the dependent variable, PsyCap and its components as mediators (as shown in Figure 1), and age, gender, educational situation and marital status as covariates. All study variables were centralized before regression analysis to account for differences in scale scores. The first step in the analysis was to determine the association between WPV and professional identity (the c path) and the second was to estimate the mediating role (the $\mathrm{a} \times \mathrm{b}$ products) of PsyCap. A bias-corrected and accelerated 95\% confidence interval (BCa 95\% CI) was determined for each $\mathrm{a} \times \mathrm{b}$ product, and a $\mathrm{BCa} 95 \% \mathrm{CI}$ excluding 0 indicated a significant mediation. The bootstrap estimate presented in our study was based upon 5,000 bootstrap samples.

All analyses were conducted using SPSS for Windows, Version 21.0, with two-tailed probability value of $<0.05$ considered to be statistically significant.

\section{Results}

\section{Demographic characteristics of subjects of professional identity}

Demographic variables of participants and group differences on professional identity are shown in Table 1. The participants were in the average age of $37.37 \pm 9.79$, 44.12\% (439) were above 40 years old. Of these participants, $54.47 \%$ (542) were men. The educational degree of $72.96 \%$ (726) doctors were: junior college or below. $64.72 \%$ (644) were married or cohabiting. The score of professional identity in the age group of $\geq 40$ years was significantly higher than those in $\leq 30$ and 31-39 years groups, respectively $(F=8.29, \quad P<0.01)$. Gender was not significantly related to professional identity. The score of professional identity among doctors with a master or higher educational degree was significantly higher than that of subjects with a college or lower educational situation $(t=12.05, P<0.01)$. The score of professional identity with a married or cohabited status was higher than that of subjects with a single and divorced, widow and separated situation $(F=20.36$, $P<0.01)$.

\section{Correlations among WPV, PsyCap and professional identity}

Results of Pearson correlation between the study variables were shown in Table 2. WPV was negatively correlated with professional identity and negatively associated with PsyCap, which was positively correlated with professional

Step1
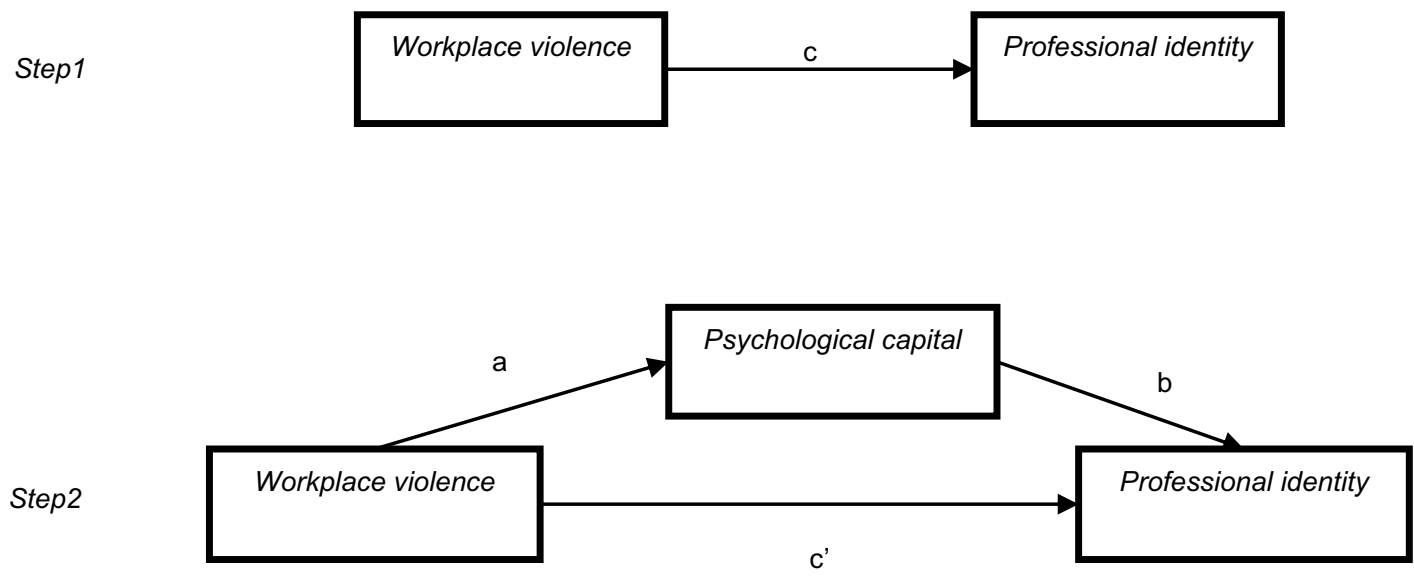

Figure I Theoretical model of the mediating role of PsyCap on the association between WPV and professional identity. c: association of WPV with professional identity; a: association of WPV with PsyCap; b: association between PsyCap and professional identity after controlling for the covariates; c': association of WPV with professional identity after adding PsyCap as a mediator.

Abbreviations: WPV, workplace violence; PsyCap, psychological capital. 
Table I Mean scores of professional identity according to demographic characteristics of participants $(n=995)$

\begin{tabular}{|c|c|c|c|c|}
\hline Variables & n (\%) & mean \pm SD & t/F-value & $P$-value \\
\hline Age (years) & & & 8.29 & $<0.01$ \\
\hline$\leq 30$ & $265(26.63)$ & $27.35 \pm 9.61$ & & \\
\hline $31-39$ & $291(29.25)$ & $29.84 \pm 8.04$ & & \\
\hline$\geq 40$ & $439(44.12)$ & $29.91 \pm 8.44$ & & \\
\hline Gender & & & 2.21 & 0.14 \\
\hline Male & $542(54.47)$ & $28.83 \pm 8.86$ & & \\
\hline Female & $453(45.53)$ & $29.66 \pm 8.54$ & & \\
\hline Educational situation & & & 12.05 & $<0.01$ \\
\hline Undergraduate and below & $726(72.96)$ & $28.63 \pm 8.60$ & & \\
\hline Master and above & $269(27.04)$ & $30.78 \pm 8.85$ & & \\
\hline Marital status & & & 20.36 & $<0.01$ \\
\hline Single/divorced/widow/separated & 351 (35.28) & $27.54 \pm 10.14$ & & \\
\hline Married/cohabitation & $644(64.72)$ & $30.12 \pm 7.70$ & & \\
\hline
\end{tabular}

Table 2 Correlations among WPV, PsyCap and professional identity

\begin{tabular}{|c|c|c|c|c|c|c|c|c|c|c|}
\hline & Mean & SD & I & 2 & 3 & 4 & 5 & 6 & 7 & 8 \\
\hline I. Age & 37.37 & 9.79 & 1 & & & & & & & \\
\hline 2. WPV & 5.23 & 4.07 & $0.10 * *$ & 1 & & & & & & \\
\hline 3. Self-efficacy & 22.26 & 6.65 & $-0.08 *$ & $-0.29 * *$ & I & & & & & \\
\hline 4. Hope & 22.36 & 6.34 & -0.06 & $-0.22^{* *}$ & $0.84^{* *}$ & I & & & & \\
\hline 5. Resilience & 22.07 & 4.92 & -0.01 & $-0.33^{* *}$ & $0.76 * *$ & $0.79 * *$ & I & & & \\
\hline 6. Optimism & 22.00 & 3.20 & -0.03 & $-0.36 * *$ & $0.70 * *$ & $0.67 * *$ & $0.77^{* *}$ & 1 & & \\
\hline 7. PsyCap & 88.69 & 19.22 & -0.06 & $-0.32 * *$ & $0.93 * *$ & $0.93 * *$ & $0.91 * *$ & $0.824 * *$ & I & \\
\hline 8. Professional identity & 29.21 & 8.72 & $0.11 * *$ & $-0.37^{* *}$ & $0.50 *$ & $0.49 * *$ & $0.50 * *$ & $0.46^{* *}$ & $0.54 * *$ & I \\
\hline
\end{tabular}

Notes: $* P<0.05 ; * * P<0.01$ (two-tailed).

Abbreviations: WPV, workplace violence; PsyCap, psychological capital.

identity. Four dimensions of PsyCap: self-efficacy, hope, resilience and optimism were positively associated with professional identity, respectively.

\section{Association of WPV and PsyCap with professional identity}

The results of hierarchical multiple regression on the associations of WPV and PsyCap and its components with professional identity were presented in Table 3. Each block of the independent variables made a significant contribution to the variance of professional identity. After adjusting for age, gender, marital status and educational situation in block 2, WPV was negatively associated with professional identity $(\beta=-0.37 ; P<0.01)$. WPV explained $13.19 \%$ of the variance of the dependent variable. In block $3^{\prime} \mathrm{s}$ model 1 , self-efficacy $(\beta=0.15$; $P<0.01)$ and hope $(\beta=0.21 ; P<0.01)$ were positively associated with professional identity. However, resilience and optimism were not significantly associated with professional identity $(P>0.05)$. These positive psychological constructs accounted for additional $19.24 \%$ of the variance. In block 3's model 2, PsyCap was significantly and positively associated with professional identity ( $\beta=0.47 ; P<0.01$ ), accounting for additional $19.13 \%$ of the variance. When PsyCap and its components were added, the absolute values of regression coefficients of WPV on professional identity were decreased. Thus, PsyCap and its components could probably function as mediators in the association of WPV with the professional identity.

\section{The mediating role of PsyCap in the relationship between WPV and professional identity}

Based on the results of hierarchical multiple regression in Table 3, asymptotic and resampling strategies were used to 
Table 3 Hierarchical multiple regression results for professional identity

\begin{tabular}{|c|c|c|c|c|}
\hline \multirow[t]{3}{*}{ Variables } & \multicolumn{4}{|c|}{ Professional identity } \\
\hline & \multirow{2}{*}{$\begin{array}{l}\text { Block } \\
\text { I }(\beta)\end{array}$} & \multirow{2}{*}{$\begin{array}{l}\text { Block } \\
2(\beta)\end{array}$} & \multicolumn{2}{|c|}{ Block $3(\beta)$} \\
\hline & & & $\begin{array}{l}\text { Model } \\
\text { I }\end{array}$ & $\begin{array}{l}\text { Model } \\
2\end{array}$ \\
\hline \multicolumn{5}{|l|}{ Block I } \\
\hline Age & $0.08 *$ & $0.13 * *$ & $0.16 * *$ & $0.15^{* *}$ \\
\hline Gender & 0.05 & 0.04 & 0.01 & 0.01 \\
\hline Marital status & $0.11 * *$ & $0.08 *$ & 0.04 & 0.03 \\
\hline Educational situation & $0.11 * *$ & $0.07^{*}$ & 0.01 & 0.01 \\
\hline \multicolumn{5}{|l|}{ Block 2} \\
\hline WPV & & $-0.37^{* *}$ & $-0.24 * *$ & $-0.24 * *$ \\
\hline \multicolumn{5}{|l|}{ Block 3} \\
\hline Self-efficacy & & & $0.15 * *$ & \\
\hline Hope & & & $0.21^{* *}$ & \\
\hline Resilience & & & 0.08 & \\
\hline Optimism & & & 0.07 & \\
\hline PsyCap & & & & $0.47 * *$ \\
\hline$\underline{F}$ & $10.27^{* *}$ & $41.02 * *$ & $62.67 * *$ & $93.84^{* *}$ \\
\hline$\overline{\text { Adjusted }} R^{2}$ & 0.04 & 0.17 & 0.36 & 0.36 \\
\hline$\Delta R^{2}$ & 0.04 & 0.13 & 0.19 & 0.19 \\
\hline
\end{tabular}

Notes: Educational situation: undergraduate or lower; master or higher Marital status: single/divorced/widow/separated; married/cohabitation. $* P<0.05 ; * * P<0.01$ (two-tailed).

Abbreviations: WPV, workplace violence; PsyCap, psychological capital.

examine the mediating roles of PsyCap and its components. As shown in Table 4, the association between WPV and professional identity (the c path) was examined. WPV had a negatively relation with professional identity. In addition, WPV has a negative association with PsyCap (a $=-0.29, P<0.01)$ and its four components $(\mathrm{a}=-0.26$, $-0.19,-0.31,-0.34$ respectively, $P<0.01)$. Self-efficacy, hope and PsyCap have significant and positive correlations with professional identity (the $\mathrm{b}$ path), but resilience and optimism were not significantly correlated with professional identity (the $\mathrm{b}$ path). Therefore, self-efficacy (a*b $=-0.04$, BCa 95\% CI: $(-0.08,-0.01) ; P<0.01)$, hope $(\mathrm{a} * \mathrm{~b}=-0.04, \mathrm{BCa} 95 \% \mathrm{CI}:(-0.08,-0.01) ; P<0.01)$ and PsyCap (a*b $=-0.13$, BCa 95\% CI: $(-0.18,-0.10)$; $P<0.01)$ partially and significantly mediated the association between WPV and professional identity. The indirect pathways between WPV and professional identity (the c' path) remained significant when self-efficacy, hope or PsyCap was included in the model as a mediator.

To estimate the effect size of the mediating pathway, we calculated the proportion of the total effect of the independent variable on the dependent variable (c) that was mediated by self-efficacy, hope and PsyCap with the formula $\left(a^{*} b\right) / c$. The proportion of self-efficacy, hope and PsyCap mediation was $10.73 \%, 10.77 \%, 36.22 \%$ for professional identity, respectively.

\section{Discussion}

In this study, we explored the associations of WPV, PsyCap and its four components (self-efficacy, hope, resilience, and optimism) with professional identity, as well as examined the mediating effect of PsyCap and its components in this relationship among Chinese doctors. WPV was found to be negatively related to professional identity, which was consistent with Luthans' research. ${ }^{19}$ One of the proper explanations is: when experiencing WPV physically or mentally, doctors will suffer from poor productivity, lower quality of work and a decline in individual sense of accomplishment. Besides, doctors will have difficulties dealing with the relationships with patients, employers and colleagues. ${ }^{35,36}$ The series of behavior will in turn lead to doctors doubting about their

Table 4 WPV as the independent variable and PsyCap and its components as mediators in the regression analysis

\begin{tabular}{|c|c|c|c|c|c|}
\hline \multirow[t]{2}{*}{ Mediators } & \multicolumn{4}{|c|}{ Path coefficients } & \multirow[t]{2}{*}{ a*b (BCa $95 \% \mathrm{Cl})$} \\
\hline & c & $\mathbf{a}$ & b & c' & \\
\hline Self-efficacy & $-0.37^{* *}$ & $-0.26 * *$ & $0.15^{* *}$ & $-0.24 * *$ & $-0.04(-0.08,-0.01)$ \\
\hline Hope & $-0.37 * *$ & $-0.19 * *$ & $0.21 * *$ & $-0.24 * *$ & $-0.04(-0.08,-0.01)$ \\
\hline Resilience & $-0.37^{* *}$ & $-0.3 I^{* *}$ & 0.08 & $-0.24^{* *}$ & $-0.02(-0.08,0.02)$ \\
\hline Optimism & $-0.37 * *$ & $-0.34 * *$ & 0.07 & $-0.24 * *$ & $-0.02(-0.06,0.02)$ \\
\hline PsyCap & $-0.37^{* *}$ & $-0.29 * *$ & $0.47^{* *}$ & $-0.24 * *$ & $-0.13(-0.18,-0.10)$ \\
\hline
\end{tabular}

Notes: c: the association of WPV with professional identity; a: the association of WPV with PsyCap; b: the association of PsyCap with professional identity after controlling for the covariates; c': the association of WPV with professional identity after adding PsyCap as a mediator; a*b: the product of a and b; BCa $95 \%$ Cl: the bias-corrected and accelerated $95 \%$ confidence interval.

Age, gender, marital status and educational situation were covariates.

Abbreviations: WPV, workplace violence; PsyCap, psychological capital. **P<0.0I (two-tailed). 
original choice as a doctor and the low level of professional identity. In the current study, WPV was negatively related to professional identity, which supported our hypothesis. Therefore, to alleviate the effect caused by WPV, hospital administrators should pay attention to the risk of WPV demonstrated by these findings. Some interventions should be conducted to decrease WPV among doctors. As an example, a better working environment should be established by measures of organizational development in hospitals. ${ }^{37,38}$ Besides, hospital administrators should enhance the security system to decrease the level of WPV.

PsyCap is an important concept of organizational behavior. Luthans and colleagues ${ }^{30}$ reported that higher levels of PsyCap enhance personal confidence and increased effort to pursue success. PsyCap could also preserve one's will to achieve a goal and increase the positive psychological capacity to handle with difficult problems. Other researches related to doctors also have paid attention to the development of PsyCap. ${ }^{39,40}$ To our knowledge, PsyCap was identified as a mediator in some other relationships. ${ }^{12,41}$ In our study, PsyCap and its components were found to be positively related to professional identity among Chinese doctors. This finding showed that PsyCap and the four components were positive resources for improving professional identity.

Our study also found that PsyCap mediated in the association between WPV and professional identity among Chinese doctors. This suggested that WPV could be harmful to PsyCap, ${ }^{11}$ and decrease the level of doctors' PsyCap, so as to lead to doctors' low level of professional identity. Regarding the PsyCap components, self-efficacy and hope mediated the effects of WPV on professional identity. This result suggested that WPV can be harmful to self-efficacy and hope. WPV may also lead to doctors' low level of professional identity. The possible explanation is that doctors with high level of PsyCap can be adapted to WPV by working harder as well as bearing heavier psychological burden in order to balance a high level of initiative. $^{42}$ This suggests that hospital managers should improve doctors' accessible possibilities of PsyCap, which plays a positive role, while some measures should be taken to reduce the level of WPV. Besides, doctors should cultivate their PsyCap to prevent the negative effects caused by WPV on professional identity. Additionally, according to the results that self-efficacy and hope of PsyCap play a mediating role in the relationship between WPV and professional identity, hospital administration should emphasize the investment in self-efficacy and hope of PsyCap to increase the level of professional identity. $^{32}$

Empirical studies suggested that the four components of PsyCap (self-efficacy, hope, resilience, and optimism) can be manipulated using effective measures. Besides, psychological capital intervention (PCI) training model has been developed for this purpose. ${ }^{43}$ Therefore, measures of enhancing PsyCap for Chinese doctors should be developed as soon as possible. People should particularly pay more attention to improving hope and self-efficacy. For hope improvement, several appropriate and challenging job goals should be set for doctors to help them strengthen their willpower. Meanwhile, doctors should pay more attention to their individual career development to increase the level of hope. ${ }^{32}$ For improving self-efficacy, administrators should encourage doctors to treat past failures and setbacks as valuable experiences, to build a positive attribution style, and to improve their capacity to discover and pursue different opportunities. $^{12,44,45}$

However, some limitations should be illustrated in the present study. First, due to the nature of cross-sectional study, causal relations among study variables could not be drawn. The results of this study should be confirmed by a longitudinal study. Second, We randomly selected one large hospital ( $>500$ beds) in each district in Dalian city. Therefore, the sample may not be completely representative of all Chinese doctors. We will extend the investigating areas in the future research.

\section{Conclusion}

The study found that PsyCap serve as a mediator between WPV and professional identity. The WPV was negatively associated with professional identity, whereas PsyCap and its dimensions were positively associated with professional identity. Furthermore, PsyCap was shown to play a role in partially mediating the effect of WPV on professional identity. Besides, two dimensions of PsyCap: self-efficacy and hope could mediate the relationship between WPV and professional identity. Importantly, since PsyCap can be measured and developed, administrators should develop interventions to enhance professional identity.

\section{Acknowledgments}

This work was supported by grant from the National Natural Science Foundation of China (No. 71673300). The author would like to thank all the teachers and 
teammates who assisted in obtaining written informed consent for the survey and in distributing questionnaires to the subjects.

\section{Author contributions}

All authors contributed to data analysis, drafting and critically revising the article, gave final approval of the version to be published, and agree to be accountable for all aspects of the work.

\section{Disclosure}

The authors report no conflicts of interest in this work.

\section{References}

1. Cruess RL, Cruess SR, Boudreau JD, Snell L, Steinert Y. Reframing medical education to support professional identity formation. Acad Med. 2014;89(11):1446-1451. doi:10.1097/ACM.0000000000000427

2. Clark CS. The nursing shortage as a community transformational opportunity an update. Adv Nurs Sci. 2010;33(1):35-52. doi:10.1097/ ANS.0b013e3181c9e1c4

3. Fang Y J, Zeng Y, Chen D Y, Hu K S, Li W J. Analysis on the young physicians' professional identity status Quo: taking two tertiary hospitals in Shantou as an example. Shantou, China: Medical College of Shantou University; 2018. (in Chinese). Available from: http://kns.cnki.net/KCMS/detail/detail.aspx? $\mathrm{dbcode}=\mathrm{CJFQ} \& \mathrm{dbname}=\mathrm{CJFDLAST} 2018 \&$ fil en a me $=$ XBYX201804010\&v=MTA5NjVMS2 VadWR0Rnkvb1ZMel BQUy9TZHJHNEg5bk1xNDIFWk1SOGVYMUx1eFITN0RoMVQ zcVRyV00xRnJDVVI=. Accessed August 4, 2018.

4. Ji X H, Wang W J, Hou S, Ren S S, Li M M. Study on the status and the influence factors of professional identity of medical students. Jining Medical University: Jining, China; 2015. (in Chinese). Available from: http://kns.cnki.net/KCMS/detail/detail.aspx?dbcode=CJFQ\&dbname= C J F D L A S T $2015 \&$ fi 1 en a m e = J N Y Y $201501024 \& \mathrm{v}=$ MzI1ODBMeVBTZDdHNEg5VE1ybzlIWUISOGVYMUx1eFITN0 RoMVQzcVRyV00xRnJDVVJMS2VadWR0RnkvblZiN0w $=$. Accessed February 1, 2015.

5. Chen M. Research on influencing about doctor-patient relationship on occupational well-being of doctors: the role of mediating effect of professional identity and moderating effect of general self-efficacy (in Chinese) [dissertation]. Accra: Southwest University of Finance and Economics, Chengdu, China; 2016. Available from: http://www. wanfangdata.com.cn/details/detail.do?_type=degree\&id=J0129317. Accessed March, 2016.

6. Guo MW, Liang WJ. 2012. The status analysis of the town doctor's working environment in Hunan Zhuzhou six regions (in Chinese). Available from: http://jour.duxiu.com/JourDetail.jsp? $\mathrm{dxNumber}=100202480486 \& \mathrm{~d}=\mathrm{F} 4 \mathrm{CDF} 0 \mathrm{E} 88 \mathrm{~EB}$ A9E06D2FC5B 925D9D6487\&fenlei=1604110201. Accessed May 22, 2012. doi:10.1094/PDIS-11-11-0999-PDN

7. Kovalčíková N, Pavelek L, Slaná M, Žáková M. Professional identity perception of hospital social workers in Slovakia. ERIS Web J. 2014;5 (2):15-24.

8. Qiuling AN. The effect factors on social worker's professional identity. J East China Univ Sci Technol. 2010;25(2):39-47.

9. White MT, Borges NJ, Geiger S. Perceptions of factors contributing to professional identity development and specialty choice: a survey of third- and fourth-year medical students. Ann Behav Sci Med Educ. 2011;17(1):18-23. doi:10.1007/BF03355144
10. Saarela KL, Tech NIL. Workplace violence in Finland: high-risk groups and preventive strategies. Am J Ind Med. 1999;36 (S1):80-81.

11. Shi J, Wang S, Zhou P, et al. The frequency of patient-initiated violence and its psychological impact on physicians in china: a cross-sectional study. PLoS One. 2015;10(6):e0128394. doi:10.1371/ journal.pone. 0128394

12. Guan J. Origin and prevention of workplace violence in health care in China: legal and ethical considerations. Chin Med J (Engl). 2017;130 (14):1731-1736. doi:10.4103/0366-6999.209888

13. Xing K, Zhang X, Jiao M, et al. Concern about workplace violence and its risk factors in chinese township hospitals: a cross-sectional study. Int J Environ Res Public Health. 2016;13(8):811. doi:10.3390/ ijerph13121252

14. Wynne R, Clarkin N, Cox T, Griffith A Guidance on the prevention of violence at work. Office for official publications of the European communities; 1997.

15. Saines BJC. Violence and aggression in A\&E: recommendations for action. Accid Emerg Nurs. 1999;7(1):8-12.

16. Arnetz JE, Arnetz BB. Medicine. Violence towards health care staff and possible effects on the quality of patient care. Soc Sci. 2001;52 (3):417-427.

17. Laschinger HKS, Grau AL. The influence of personal dispositional factors and organizational resources on workplace violence, burnout, and health outcomes in new graduate nurses: A cross-sectional study. Int J Nurs Stud. 2012;49(3):282-291. doi:10.1016/j. ijnurstu.2011.09.004

18. Yao Y, Wang W, Wang F, Yao W, Health E. General self-efficacy and the effect of hospital workplace violence on doctors' stress and job satisfaction in China. Int J Occup Med. 2014;27(3):389399.

19. Luthans F, Youssef CM. Human, social, and now positive psychological capital management: investing in people for competitive advantage. Organ Dyn. 2004;33(2):143-160. doi:10.1016/j. orgdyn.2004.01.003

20. Wang Y, Chang Y, Fu J, Wang L. Work-family conflict and burnout among Chinese female nurses: the mediating effect of psychological capital. BMC Public Health. 2012;12(1):915. doi:10.1186/14712458-12-915

21. Avey JB, Luthans F, Jensen SM. Psychological capital: A positive resource for combating employee stress and turnover. Hum Resour Manage. 2010;48(5):677-693. doi:10.1002/hrm.20294

22. Jo H, Ra YA, Lee J, Kim WH. Impact of dysfunctional career thoughts on career decision self-efficacy and vocational identity. Career Dev Q. 2016;64(4):333-344. doi:10.1002/ cdq. 12069

23. Wang Y, Liu L, Wang J, Wang L. Work-family conflict and burnout among Chinese doctors: the mediating role of psychological capital. J Occup Health. 2012;54(3):232. doi:10.1539/ joh.11-0243-OA

24. Tyler D, McCallum RS. Assessing the relationship between competence and job role and identity among direct service counseling psychologists. J Psychoeduc Assess. 1998;16(2):135-152. doi:10.1177/ 073428299801600203

25. Hong N A study on the relationship between perception, personality, professional identity and emotional exhaustion of flight attendants' emotional expression rules [dissertation]. Accra: Capital Normal University, Beijing, China; 2007. (In Chinese). Available from: http://kns.cnki.net/ $\mathrm{KCMS} / \mathrm{detail} / \mathrm{detail}$.asp $\mathrm{x}$ ?dbcode $=\mathrm{CMFD} \& \mathrm{dbname}=$ CMFD2007\&filename $=2007076111$.nh\&uid $=$ WEEvREcwSIJHSld Ra1FhdXNXa0d1YWxnS1dRbEsvSzRmaW40Vlg4VUU0OD0= \$9A4hF_YAuvQ5obgVAqNKPCYcEjKensW4IQMovwHtwkF4V YPoHbKxJw!!\&v=MTU5NzBETnJwRWJQSVI4ZVgxTHV4WV M3RGgxVDNxVHJXTTFGckNVUkxLZVp1ZHJGeTdrVTcvTIYxMjd HYk8vR04=. Accessed June, 2007. doi: 10.1094/PDIS-91-4-0467B 
26. Schat ACH, Kelloway EK. Reducing the adverse consequences of workplace aggression and violence: the buffering effects of organizational support. J Occup Health Psychol. 2003;8(2):110. doi:10.1037/ 1076-8998.8.2.110

27. Wang PX, Wang MZ, Bai Q, et al. [Path analysis on workplace violence affecting work ability, job satisfaction and turnover intent in health professionals in Shangqiu City]. Wei Sheng Yan Jiu. 2006;35 (6):785-788.

28. Wang PX Study on Medical Workplace Violence and Theory Model [dissertation]. Accra: Sichuan University: Sichuan, China, 2006. (In Chinese). Available from: http://kns.cnki.net/KCMS/detail/detail.aspx? dbcode $=$ CDFD\&dbname $=$ CDFD9908\&filename $=$ 2006189171.nh\&uid $=$ WEEvREcwS1JHSldRa1FhdXNXa0d1YWxnS1dRbEsvSzRmaW40V1 g4VUU0OD0 $=\$ 9 A 4 \mathrm{hF}$ YAuvQ5obgVAqNKPCYcEjKensW4IQMovw HtwkF4VYPoHbKxJw!! \&v=Mjc2ND11ZHJGeTdsVjdyT1Yx MjdHTEt3RjlETHJwRWJQSVI4ZVgxTHV4WVM3RGgxVDNxVHJ XTTFGckNVUkxLZVo=. Accessed April, 2006.

29. Chen SY, Lin SW, Ruan QS, Li HY, Wu SY. Workplace violence and its effect on burnout and turnover attempt among Chinese medical staff. Arch Environ Occup Health. 2016;71(6):330-337. doi:10.1080/ 19338244.2015.1128874

30. Luthans F, Avolio BJ, Avey JB, Norman SM. Positive psychological capital: measurement and relationship with performance and satisfaction. Pers Psychol. 2010;60(3):541-572. doi:10.1111/j.17446570.2007.00083.x

31. Ding Y, Yang Y, Yang X, et al. The mediating role of coping style in the relationship between psychological capital and burnout among Chinese nurses. PLoS One. 2015;10(4):e0122128. doi:10.1371/journal.pone.0122128

32. Liu L, Chang Y, Fu J, Wang J, Wang L. The mediating role of psychological capital on the association between occupational stress and depressive symptoms among Chinese physicians: a cross-sectional study. BMC Public Health. 2012;12(1):219. doi:10.1186/14712458-12-219

33. Kan D, Yu XS. Occupational stress, work-family conflict and depressive symptoms among Chinese bank employees: the role of psychological capital. Int J Environ Res Public Health. 2016;13(1):134 doi:10.3390/ijerph13121252

34. Preacher KJ, Hayes AF. Asymptotic and resampling strategies for assessing and comparing indirect effects in multiple mediator models. Behav Res Methods. 2008;40(3):879-891.
35. Eslamian J, Akbarpoor AA, Hoseini SA, Research M. Quality of work life and its association with workplace violence of the nurses in emergency departments. Iranian J Nurs. 2015;20 (1):56-62

36. Roldán GM, Salazar IC, Garrido L, Ramos JM. Violence at work and its relationship with burnout, depression and anxiety in healthcare professionals of the emergency services. Health. 2013;5(02):193. doi:10.4236/health.2013.52027

37. Netemeyer RG, Boles JS, Mcmurrian R. Development and validation of work-family conflict and family-work conflict scales. $J$ Appl Psychol. 1996;81(4):400-410. doi:10.1037/00219010.81.4.400

38. Yavas U, Babakus E, Karatepe OM. Attitudinal and behavioral consequences of work-family conflict and family-work conflict. Int J Serv Indust Manage. 2013;19(1):7-31. doi:10.1108/ 09564230810855699

39. Zheng YS, Zhang LL, University MN. The effect of compassion fatigue on work engagement: the mediating role of psychological capital. J Mudanjiang Normal Univ. 2017(02);130-135.

40. Fu J, Sun W, Wang Y, Yang X, Wang L. Improving job satisfaction of Chinese doctors: the positive effects of perceived organizational support and psychological capital. Public Health. 2013;127 (10):946-951. doi:10.1016/j.puhe.2012.12.017

41. Wang Y, Yao LT, Liu L, et al. The mediating role of self-efficacy in the relationship between Big five personality and depressive symptoms among Chinese unemployed population: a cross-sectional study. BMC Psychiatry. 2014;14:61. doi:10.1186/1471244X-14-61

42. Zhong L. Review of psychological capital research. Adv Psychol Sci. 2007;15(3):482-487.

43. Russo SD, Stoykova P. Psychological capital intervention (PCI): A replication and extension. Hum Resour Dev Q. 2015;26(3):329-347. doi:10.1002/hrdq.2015.26.issue-3

44. Luthans F, Avey JB, Avolio BJ, Norman SM, Combs GM. Psychological capital development: toward a micro-intervention. $J$ Organ Behav. 2010;27(3):387-393. doi:10.1002/job.373

45. Luthans F, Avey JB, Patera JL. Experimental analysis of a webbased training intervention to develop positive psychological capital. Acad Manage Learn Edu. 2008;7(2):209-221. doi:10.5465/ amle.2008.32712618
Psychology Research and Behavior Management is an international, peer-reviewed, open access journal focusing on the science of psychology and its application in behavior management to develop improved outcomes in the clinical, educational, sports and business arenas. Specific topics covered in the journal include: Neuroscience, memory and decision making; Behavior modification and management; Clinical applications; Business and sports performance management; Social and developmental studies; Animal studies. The manuscript management system is completely online and includes a very quick and fair peer-review system, which is all easy to use. Visit http://www. dovepress.com/testimonials.php to read real quotes from published authors. 